\title{
Impact of curcumin on replicative and chronological aging in the Saccharomyces cerevisiae yeast
}

\author{
Karolina Stępień · Dominik Wojdyła $\cdot$ Katarzyna Nowak $\cdot$ Mateusz Mołoń $\mathbb{B}$
}

Received: 20 August 2019/ Accepted: 22 October 2019/Published online: 28 October 2019

(C) The Author(s) 2019

\begin{abstract}
Curcumin is a biologically active compound of vegetable origin which has a hormetic effect. Pro-health and anti-aging properties of curcumin have been known for years. The main benefit of curcumin is thought to be its anti-oxidative action. Despite vast amount of data confirming age-delaying activity of curcumin in various groups of organisms, so far little has been discovered about curcumin's impact on cell aging in the experimental model of the Saccharomyces cerevisiae budding yeast. We have been able to demonstrate that curcumin significantly increases oxidative stress and accelerates replicative and chronological aging of yeast cells devoid of antioxidative protection (with SOD1 and SOD2 gene deletion) and deprived of DNA repair mechanisms (RAD52). Interestingly, curcumin delays aging, probably through hormesis, of the wild-type strain BY4741.
\end{abstract}

Keywords Aging - Curcumin · Hypertrophy · Oxidative stress · Yeast

K. Stępień · D. Wojdyła · K. Nowak · M. Mołoń ( $\square)$ Department of Biochemistry and Cell Biology, University of Rzeszow, Zelwerowicza 4, 35-601 Rzeszow, Poland e-mail: mateuszmolon@univ.rzeszow.pl

\section{Introduction}

Curcumin is a biologically active compound of vegetable origin. It was isolated for the first time from rhizomes of the perennial Curcuma longa plant (Vogel 1815). The compound has been widely used in food industry as a colourant or a spice (curcuma). However, curcumin raises interest primarily due to its predominantly pro-health action. The substance is characterised with a diverse biological activity related to anti-inflammatory, anti-oxidative, antimicrobial, proapoptotic and antineoplastic effect. Therefore, curcumin has had a very long tradition of use in natural medicine as it has no adverse effects. However, due to hydrophobic nature of the curcumin molecule, low absorption, and quick metabolism and elimination, the biological availability of curcumin is very low (Hewlings and Kalman 2017).

At the molecular level curcumin modulates a broad range of signalling molecules. It may increase or decrease their activity, depending on the target structure. The mechanism can be activated in two ways: by direct or indirect curcumin bounding. Indirect modulation refers to transcription factors, enzymes, inflammatory mediators, kinases, drug resistance proteins, adhesion molecules, growth factors, cell cycle regulation proteins and cell survival proteins. Direct action of curcumin refers to inflammatory molecules, kinases, reductases, histone acetyltransferases, integrins, DNA methyltransferase 1, carrier 
proteins and metal ions (Barchitta et al. 2019; Gupta et al. 2012).

The strong antioxidative effect of curcumin is connected with its ability to remove reactive oxygen species (ROS), including the dangerous hydroxyl radical, superoxide anion radical and nitric oxide (Toda et al. 1985). Moreover, it is able to activate genes of major antioxidant enzymes (Menon and Sudheer 2007). Furthermore, curcumin inhibits increase of the lipid peroxide level and protects lipids against oxidation (Wei et al. 2006).

Curcumin's anti-inflammatory properties result from inhibiting activation of the inflammation factor NF- $\mathrm{KB}$, which leads to lowering of inflammatory protein synthesis. Curcumin inhibits activation of the transcription factor through the IкB kinase complex (IKK), which is the NF- $\mathrm{KB}$ activator (Plummer et al. 1999). Antineoplastic properties of curcumin are connected with inhibition of cancer cell proliferation and induction of cell death (Duvoix et al. 2005). Curcumin stops the process of metastasis by inhibiting metalloproteinase activity (Aggarwal et al. 2005). Curcumin is also able to inhibit angiogenesis by lowering the expression of cytokines such as vascular endothelial growth factor and fibroblast growth factor (Arbiser et al. 1998). However, the most important anti-neoplastic property of curcumin is the ability to induce apoptosis and stop proliferation of cancer cells. With regard to neoplastic cells, the proapoptotic mechanism is related to induction of apoptosis through the mitochondrial pathway connected with oxidative stress, and through the intracellular pathway dependent on the p53 protein (Lantto et al. 2009; Shishodia and Aggarwal 2002).

Curcumin is also involved in regulation of the aging process. It may have an inhibiting effect on the TOR kinase and in this way delay aging (Beevers et al. 2006). Studies have shown a relationship between the TOR kinase and IKK involved in induction of inflammatory responses. As an IKK inhibitor, curcumin further blocks NF- $\mathrm{KB}$ as well as the TOR pathway, combining anti-inflammatory and anti-aging properties. Furthermore, the anti-oxidant action of curcumin related to improvement of the redox state in aging cells may have a positive impact on the delay of aging. Further details on curcumin impact on human organism can be found in the review paper (Hewlings and Kalman 2017).

Aging is a complex and multifactorial biological process that applies to all living organisms. Aging lowers an organism's ability to respond to environmental stress. Over time, it triggers accumulation of intracellular damage and to impairment of tissue and organ function, eventually leading to the organism's death. There have been numerous hypotheses and theories to explain the mechanisms of aging. The so called free radical theory of aging, which posits the destructive impact of reactive oxygen species (ROS) on the organism (Harman 1956), has been widely discussed for many years. ROS such as superoxide anion radicals lead to oxidation of cell macromolecules, which results in their malfunctioning. As such, the theory has as many advocates as it has opponents. Today we know that free radicals are not the main cause of aging and cell death; rather, they are one of many factors contributing to cell function distortion. Compounds that are capable of scavenging free radicals or transforming them into inactive forms are part of a defence mechanism preventing damage caused by free radicals.

Therefore, the purpose of this paper is to verify the anti-aging and anti-oxidative effects of curcumin using the Saccharomyces cerevisiae budding yeast as a model. We are the first to show impact of curcumin on the aging for yeast.

For the purpose of the study, we used the haploid yeast mutants $\operatorname{sod} 1 \Delta$, sod $2 \Delta$ and $\operatorname{rad} 52 \Delta$ in the BY4741 genetic background. CuZnSOD (SOD1) is the basic form of intracellular superoxide dismutase containing copper and zinc in the active site, occurring primarily in cytoplasm. SOD1 enters the cell nucleus in response to oxidative stress to promote transcription of stress response genes. MnSOD (SOD2) located in the mitochondrial matrix contains manganese in the active site. The mitochondrial manganese superoxide dismutase protects cells against oxygen toxicity and oxidative stress (Fukai and Ushio-Fukai 2011). Rad52p participates in double-stranded DNA breaks repair. Although RAD52 is expressed during the whole cell cycle, it is induced during meiosis as a response to DNA damage factors (Cole et al. 1989).

\section{Materials and methods}

\section{Yeast strains}

The strains used in this study are haploid wild-type yeast strain BY4741 (MATa his3 leu2 met15 ura3) and isogenic mutant strains sod1 $\triangle$ (MATa his3 leu2 met15 
ura3 YJR104C::kanMX4), sod24 (MATa his3 leu2 met15 ura3 YHR008C::kanMX4), rad52 4 (MATa his3 leu2 met15 ura3 YML032C::kanMX4) (EUROSCARF).

Growth conditions

Yeast cells were grown in a standard liquid YPD medium (1\% Difco Yeast Extract, 1\% Yeast BactoPeptone, 2\% (w/v) glucose) without (control) or with $200 \mu \mathrm{M}$ and $300 \mu \mathrm{M}$ treatment curcumin on a rotary shaker at $150 \mathrm{rpm}$, or on a solid YPD medium containing $2 \%$ agar. The experiments were carried out at a the temperature of $28{ }^{\circ} \mathrm{C}$.

Kinetics of growth assay

Growth assays were carried out on liquid medium. Yeast cell suspension was incubated for $12 \mathrm{~h}$ in a shaking incubator at $28{ }^{\circ} \mathrm{C}$ (Heidolph Inkubator 1000 at $1200 \mathrm{rpm}$ ). The growth was monitored turbidimetrically in the Anthos 2010 type 17,550 microplate reader at $600 \mathrm{~nm}$ by performing measurements at $1 \mathrm{~h}$ intervals for $12 \mathrm{~h}$. The data represent the mean values from three independent experiments.

Determination of mean doubling time

The mean doubling time was calculated for each analyzed cell as described previously (Molon et al. 2016). The doubling time was calculated during the determination of the reproductive potential. The times of the first two reproductive cycles were not taken into account (the first and second doubling times are longer than those of older cells). The data represent the mean values from three independent experiments (with 45 cells used in each experiment) with a mean standard deviation (SD).

\section{Determination of budding lifespan}

The budding lifespan of individual mother yeast cells was defined as the number of mitotic cycles (buddings) during the cell's life. After overnight growth, cells were arrayed on a YPD plate without (control) or with $200 \mu \mathrm{M}$ and $300 \mu \mathrm{M}$ curcumin using a micromanipulator. The budding lifespan was determined microscopically by a routine procedure with the use of a micromanipulator as described previously (Molon et al. 2018). The number of buds formed by each mother cell signifies its reproductive potential (budding lifespan). In each experiment, forty-five single cells were analyzed. The results represent measurements for at least 90 cells analyzed in two independent experiments. The analysis was performed by micromanipulation using the Nikon Eclipse E200 optical microscope with an attached micromanipulator.

\section{Determination of total lifespan}

The total lifespan was defined as the length of life of a single mother cell expressed in units of time. The total lifespan was calculated as the sum of reproductive and post-reproductive lifespans. The reproductive lifespan was defined as the length of time between the first and the last budding, and the post-reproductive lifespan as the length of time from the last budding until cell death. The lifespan of the Saccharomyces cerevisiae yeast was determined as previously described by (Minois et al. 2005) with small modification (Molon et al. 2018). Ten microliter aliquots of an overnight grown culture of yeast were collected and transferred on YPD plates with solid medium containing Phloxine B $(10 \mu \mathrm{g} / \mathrm{mL})$ and without (control) or with $200 \mu \mathrm{M}$ and $300 \mu \mathrm{M}$ curcumin. Phloxine $\mathrm{B}$ was used to stain Saccharomyces cerevisiae dead cells. Dead yeast cells lose membrane integrity and Phloxine B entered cell space giving pink/red coloration of cytosol. In each experiment, forty-five single cells were analysed. During manipulation, the plates were kept at $28{ }^{\circ} \mathrm{C}$ for $15 \mathrm{~h}$ and at $4{ }^{\circ} \mathrm{C}$ during the night. The results represent measurements for at least 90 cells analysed in two independent experiments. The analysis was performed by micromanipulation using the Nikon Eclipse E200 optical microscope with an attached micromanipulator.

\section{Chronological life span (CLS) assays}

Chronological life span of cells incubated in minimal medium (SDC) was measured as described previously (Fabrizio and Longo 2003). Briefly, yeast were grown in SDC containing $2 \%(\mathrm{w} / \mathrm{v})$ glucose, supplemented with histidine, leucine, methionine, uracil and appropriate concentration of curcumin. Chronological life span was monitored in expired SDC medium by measuring viability in 2, 5, 8, 12, 19 and 26 days. For the quantitative measurement of survival, staining 

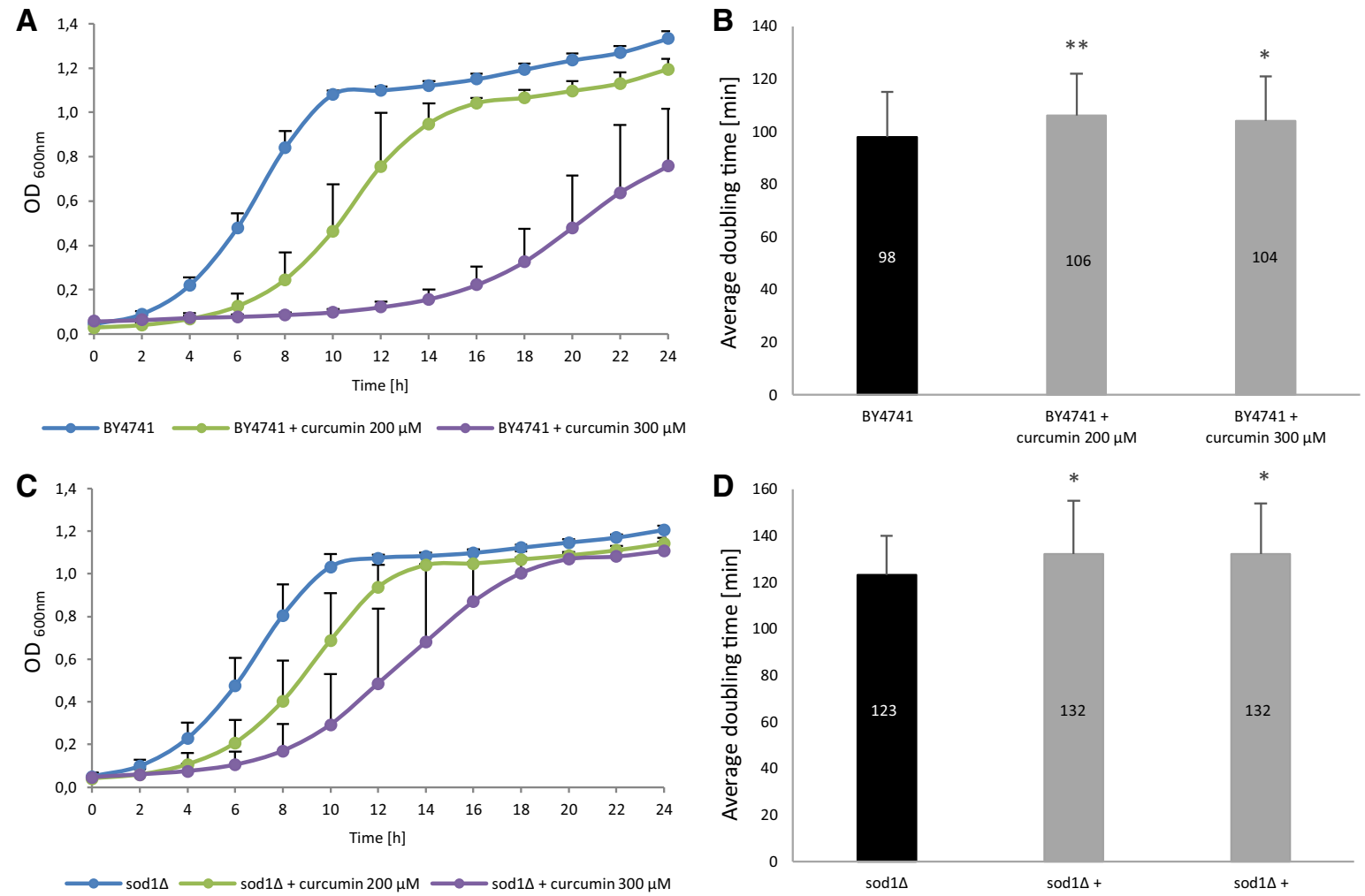

$\longrightarrow \operatorname{sod} 1 \Delta \longrightarrow \operatorname{sod} 1 \Delta+\operatorname{curcumin} 200 \mu \mathrm{M} \rightleftharpoons \operatorname{sod} 1 \Delta+\operatorname{curcumin} 300 \mu \mathrm{M}$
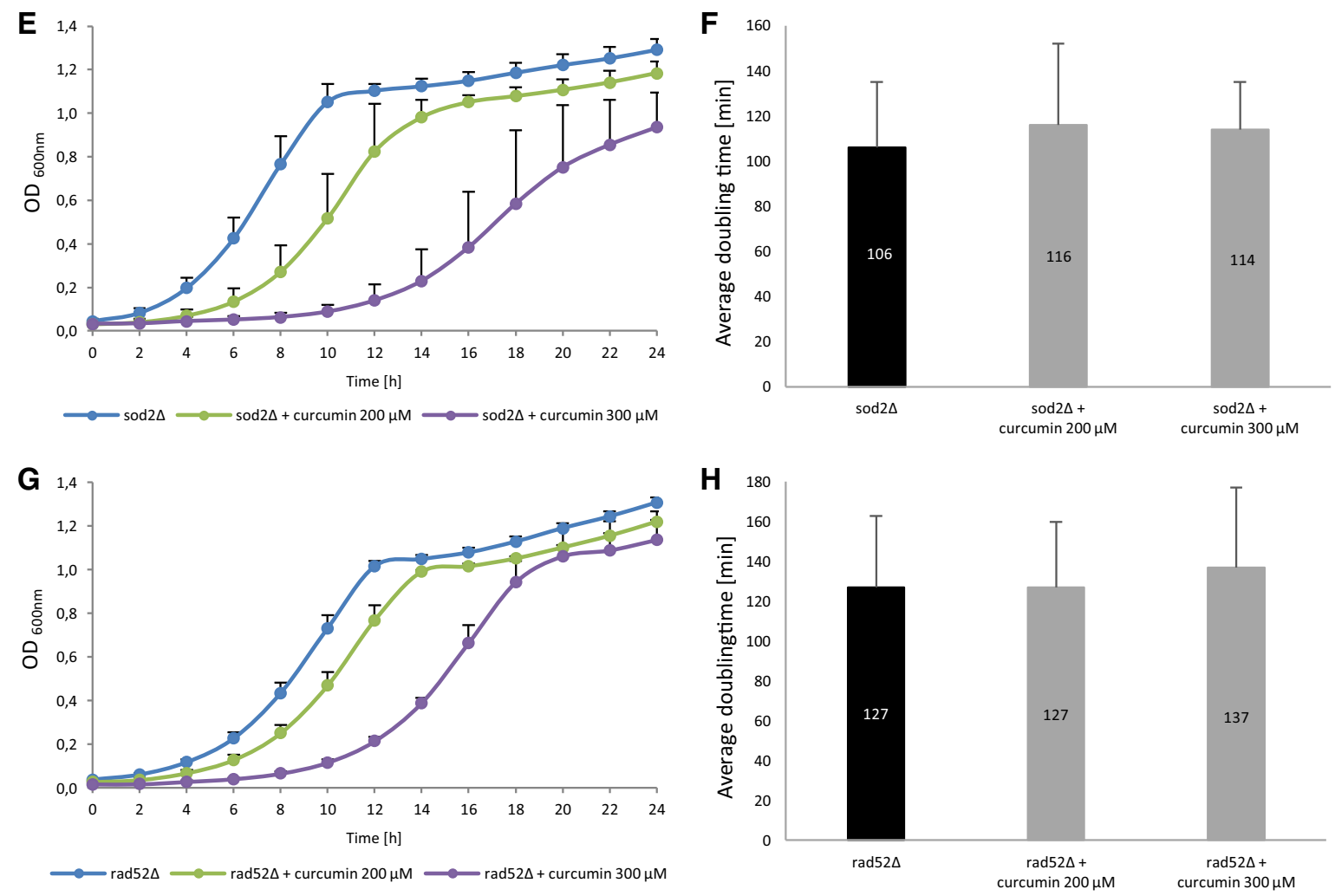
4Fig. 1 Comparison of growth kinetics (a, c, e, g) and average doubling time during reproducing $(\mathbf{b}, \mathbf{d}, \mathbf{f}, \mathbf{h})$ of the haploid wildtype yeast strain BY4741 and isogenic mutant strains sod1A, $\operatorname{sod} 2 \Delta, \operatorname{rad} 52 \Delta$ treated with curcumin. The optical density $\left(\mathrm{OD}_{600}\right)$ of the cultures was measured at different time points for up to $24 \mathrm{~h}$. Error bars represent standard deviations obtained from three independent experiments Statistical significance (b, $\mathbf{d}, \mathbf{f}, \mathbf{h})$ was assessed using ANOVA and the Dunnett's post hoc test $(* \mathrm{p}<0.05, * * \mathrm{p}<0.01, * * * \mathrm{p}<0.001)$ compared to the control (untreated). Bars indicate SD

with propidium iodide was used. The data represent the mean values from three independent experiments.

\section{Cell viability}

For determining death cells staining with propidium iodide was used. Cells were suspended in PBS and stained with $5 \mu \mathrm{g} / \mathrm{mL}$ propidium iodide (SigmaAldrich) for $15 \mathrm{~min}$ in the dark at room temperature. Fluorescence pictures were taken with Olympus BX51 microscope equipped with a DP-72 digital camera and cellSens Dimension software. Dead cells were red fluorescent. The data represent the mean values from three independent experiments.

Estimation of cell diameter

Cell volume was estimated by optical microscopy and analysis of images collected in 2, 5, 8, 12 day during the routine procedure of determining the chronological lifespan. The images were captured with the Nikon Eclipse E200 microscope equipped with the Olympus DP26 digital camera. Cell diameter (d) live cells was measured using the Olympus cellSens Standard software in various planes for each cell and the mean value was used for calculations. The data represent the mean values from three independent experiments.

Measurement of superoxide anion generation

Generation of reactive oxygen species (superoxide anion) was assessed with dihydroethidine (Invitrogen) (DHET; final concentration $18.9 \mu \mathrm{M}$ ) used standard protocols. The yeast cells from the exponential phase culture were washed with sterile water and suspended to the final density of $10^{8}$ cells $/ \mathrm{mL}$ in $100 \mathrm{mM}$ phosphate buffer $\mathrm{pH} 7.0$ containing $0.1 \%$ (w/v) glucose and $1 \mathrm{mM}$ sodium EDTA. The kinetics of fluorescence increase due to oxidation of the dihydroethidine was measured using the TECAN Infinite 200 microplate reader at $\lambda_{\text {ex }}=518 \mathrm{~nm}$ and $\lambda_{\text {em }}=605 \mathrm{~nm}$ at the temperature of $28{ }^{\circ} \mathrm{C}$. The data represent the mean values from three independent experiments.

Phenotypic analysis - a spot test for sensitivity to Congo red, Methyl methanesulfonate (MMS), sodium chloride $(\mathrm{NaCl})$, Hydrogen peroxide $\left(\mathrm{H}_{2} \mathrm{O}_{2}\right)$, Dodecyl sodium sulfate (SDS), Acetic acid and Heat shock

Yeast cultures were grown to exponential phase $\left(\mathrm{OD}_{600 \mathrm{~nm}}\right.$ between 0.8 and 1$)$ and serially diluted to different cellular concentrations as indicated. Five microliters of each cell suspension was spotted onto agar plates containing curcumin or not (control) and various concentrations of Congo red (Sigma-Aldrich), methyl methanesulfonate (Sigma-Aldrich), sodium chloride ( $\mathrm{NaCl}$ ) (Sigma-Aldrich), Hydrogen peroxide $\left(\mathrm{H}_{2} \mathrm{O}_{2}\right)$ (Sigma-Aldrich) (final concentration $\mathrm{H}_{2} \mathrm{O}_{2}$ $5 \mathrm{mM}$, incubation for $60 \mathrm{~min}$ with shaking), Dodecyl sodium sulfate (SDS) (Sigma-Aldrich), Acetic acid (Sigma-Aldrich) and Heat shock (incubation at $46{ }^{\circ} \mathrm{C}$ for $20 \mathrm{~min}$ ). Growth was registered $48 \mathrm{~h}$ after incubation at $30{ }^{\circ} \mathrm{C}$. All phenotypes described in this work were confirmed by three independent tests.

\section{Statistical analysis}

The results represent the mean $\pm \mathrm{SD}$ values for all cells tested in three or two independent experiments. The differences between the wild-type and the isogenic mutant strains were estimated using the one-way ANOVA and Dunnett's post hoc test. The values were considered significant if $* p<0.05$, $* * \mathrm{p}<0.01$ or $* * * \mathrm{p}<0.001$. Statistical analysis was performed using the Statistica 10 software.

\section{Results and discussion}

Impact of curcumin on the growth rate and mean doubling time

First, we checked whether curcumin supplementation has impact on the growth rate of yeast cells. For that purpose, we obtained the 24-h growth curve for the analysed strains. For each strain, we determined the 
control curve with no curcumin added; then we measured the growth rate of cells treated with $200 \mu \mathrm{M}$ and $300 \mu \mathrm{M}$ curcumin, respectively. In all of the analysed strains curcumin supplementation resulted in clear inhibition of the growth rate (Fig. 1a, $\mathrm{c}, \mathrm{e}, \mathrm{g})$. It should be emphasised that analysis of the growth curve shows the behaviour of the whole cell population, i.e. both the virgin cells with extended doubling time, which constitute ca. 50\% of the population, and the older cells (Molon et al. 2016). This is why in addition to obtaining a standard 24-h growth curve for each tested strain with and without curcumin supplementation, we also measured the mean doubling time during the lifetime of cells (from birth until death). In the case of the wild-type BY4741 strain, supplementation of $200 \mu \mathrm{M}$ and $300 \mu \mathrm{M}$ curcumin resulted in a statistically significant extension of the mean doubling time, with $\mathrm{p}<0.01$ and $\mathrm{p}<0.05$, respectively (Fig. 1b). Similarly, analysis of the sod1 $\Delta$ mutant showed that curcumin supplementation significantly extends the mean doubling time at $\mathrm{p}<0.05$ for both curcumin concentrations (Fig. 1d). In the case of the sod $2 \Delta$ and rad52 $\Delta$ mutants (Fig. 1f, $\mathrm{h}$ ), we noted a small increase in the mean doubling time after curcumin supplementation; however, the increase was statistically insignificant compared to the control. A comparative analysis of these two methods of doubling time estimation shows clearly that the slowdown of growth, normally presented as a growth curve, does not always show real problems with growth of all yeast cells in a population. As shown previously, it is due to the slowdown of the first few buddings (Molon et al. 2016). Our data show that in the case of the analysed strains, in most of the cases the growth was inhibited after curcumin supplementation. These results are consistent with earlier reports. Studies with the use of yeast as a model organism unanimously show that $S$. cerevisiae is sensitive to this substance and that curcumin, through various pathways and mechanisms, inhibits its growth. Minear et al. have shown that curcumin inhibits growth of the S. cerevisiae yeast through iron chelation (Minear et al. 2011). Curcumin is an effective chelator of $\mathrm{Fe}(\mathrm{III})$. In their study, Minear et al. showed that curcumin inhibits growth of wild-type strains in a dose-dependent way, and that mutants with iron homeostasis defects are hypersensitive to curcumin. They conclude that curcumin penetrates yeast cells, concentrates in the endoplasmic reticulum membranes, and reduces the intracellular iron pool. Addition of iron to the medium improved substantially the growth of curcumin-sensitive strains (Minear et al. 2011). Also, addition of curcumin to the culture resulted in extending the doubling time and delaying the cell cycle progress depending on the supply of iron, as the concurrent supplementation of iron and curcumin alleviates negative effects of the delay in growth (Minear et al. 2011). Similar results related to the growth inhibition effect in yeast treated with curcumin and the reversal of that effect by addition of iron to the culture medium were obtained by Azad et al. (Azad et al. 2013). The latter also found out that curcumin acts as an intermediary in the activity of histone proteins and chromatin-modifying enzymes, as the mutants with histones devoid of N-terminal tails and with punctate mutations are hypersensitive to curcumin. Histone proteins and chromatin modifiers are the targets of curcumin activity and therefore curcumin may interfere with cell processes (Azad et al. 2013). Curcumin also acts in an epigenetic manner. The epigenetic regulatory role of curcumin is associated mainly with inhibition of DNA methyltransferases, regulation of histone modifications via regulation of histone acetyltransferases and deacetylases, and regulation of micro RNAs. Epigenetic regulation has been extensively reviewed elsewhere (Boyanapalli and Kong 2015). Further studies have shown that the yeast mitogen-activated protein kinase (MAPK) Hog1 is essential for the response to curcumin. In addition, curcumin, through the Hog1 protein, leads to up-regulation of the GPDI gene, which is necessary during osmotic stress response (Azad et al. 2014). Curcumin has been found to be biologically active against a variety of tumour types. It induces G2/M cell cycle arrest of head and neck squamous cell carcinoma and in colorectal cancer $(\mathrm{Hu}$ et al. 2017, Jaiswal et al. 2002). Curcumin has also been found to inhibit the growth of two pancreatic cancers cell lines in a dose- and time-dependent manner (Zhu and Bu 2017).

\section{Impact of curcumin on Saccharomyces cerevisiae yeast aging processes based on the replicative and chronological aging models}

Most recent investigation provides vast amount of data on pro-health and anti-aging effects of curcumin on model organisms, yet so far little has been known on 
its impact on yeast aging. Therefore, we have been the first to measure the rate of aging of mitotically active yeast cells as well as yeast cells in the post-mitotic phase using the two accepted aging models, namely the replicative model and the chronological model.

First, we analysed curcumin impact on aging of mitotically active cells. In the standard replicative aging model, the length of life of the cell is defined as the number of daughters produced by the mother cell before the cell cycle stops irrevocably. Analyses based on that model are performed by means of physical separation of daughter cells from the mother cell under a microscope equipped with a micromanipulator (Kaeberlein 2010). In fact, the unit of replicative lifespan expresses the reproduction potential or fertility of a cell, not its real longevity. Therefore, in order to determine the actual length of life of a mitotically active cell, a new unit was proposed, namely the total lifespan (TLS), which is defined as the sum of the asexual reproduction lifespan and post-reproductive lifespan, or the time of life that passes from the last cell doubling until the cell's death (Zadrag et al. 2008).

As seen in Fig. 2a, c, e, g, curcumin supplementation had an impact on reproductive potential only in the case of the wild-type strain $(\mathrm{p}<0.05)$. In the case of the sod $1 \Delta$ and rad52 $\Delta$ mutants, curcumin statistically significantly decreased the reproductive potential of the cells (Fig. 2c, g), with $\mathrm{p}<0.001$ for sod1 $\Delta$ at $200 \mu \mathrm{M}$ curcumin concentration, and $\mathrm{p}<0.05$ for rad52 $\Delta$ at $300 \mu \mathrm{M}$ curcumin concentration. In the case of the SOD2 gene deletion, curcumin supplementation reduced reproductive capacity of the cells; however, the changes were not statistically significant (Fig. 2e).

We have also measured the total lifetime of mitotically active cells, i.e. from the birth of the cell until its death. As seen in Fig. 2b, addition of $200 \mu \mathrm{M}$ curcumin had a positive effect on the mean and maximum lifespans of the wild-type BY4741 yeast cells ( $p<0.05$ ). In the case of other strains (Fig. $2 d, f$, h), we noticed no significant impact of curcumin on the average lifespan. Furthermore, we determined the length of the period during which the cells were able to bud (reproductive lifespan) and the period during which they remained alive but unable to bud (postreproductive lifespan). In the case of the wild-type BY4741 strain, supplementation of curcumin significantly extended the reproductive lifespan, with $\mathrm{p}<0.01$ for $200 \mu \mathrm{M}$ curcumin and $\mathrm{p}<0.05$ for
$300 \mu \mathrm{M}$ curcumin, respectively (data not shown) A. In the case of the rad52 $\Delta$ strain, addition of curcumin at the $300 \mu \mathrm{M}$ concentration resulted in a significant reduction of the reproductive lifespan $(\mathrm{p}<0.01)$ (data not shown).

Subsequently, we analysed the effect that curcumin had on chronological lifespan. Chronological lifespan is the measure of the length of survival time of the yeast population during the stationary phase or postdiauxic phase. Chronological lifespan is analysed with the use of a synthetic medium with supplementation of glucose and the necessary amino acids. When the exponential growth phase of the culture is completed, glucose concentration in the medium is exhausted and becomes very low, while yeast switches from fermentative metabolism to the aerobic respiration-based metabolism (diauxic shift). In addition, cells begin catabolic utilisation of the ethanol accumulated during fermentation and obtain energy from mitochondrial oxidative phosphorylation (Fabrizio and Longo 2003). Depletion of nutrients and the carbon source results in stopping of the cell cycle, which is necessary for the purpose of chronological lifespan analysis. Intracellular damage resulting from the production of ROS in mitochondria during respiration may accumulate over the course of chronological aging and prevent the cell from re-entering the cell cycle (Kaeberlein 2010).

In the chronological aging model, curcumin supplementation had a significant positive impact on the survival rate of the wild-type BY4741 strain cells, with $\mathrm{p}<0.001$ at day 5 , day 8 and day 12 of the experiment (Fig. 3a). In the case of the sod $2 \Delta$ strain, addition of curcumin resulted in a significant decrease of the survival rate at day 5 of the experiment, with $\mathrm{p}<0.05$ after supplementation of $200 \mu \mathrm{M}$ curcumin, and $\mathrm{p}<0.01$ after supplementation of $300 \mu \mathrm{M}$ curcumin, respectively (Fig. 3c). For the sodl $\Delta$ and rad52 $\Delta$ strains, the survival rate also dropped after curcumin supplementation, although not in a statistically significant manner (Fig. 3b, d).

We also measured the cell size change kinetics over time. As shown in Fig. 4, in a post-mitotic culture the increase in cell size can be observed. We show that only hypertrophic cells are able to survive and are resistant to environmental factors, while small cells are sensitive to stress and die within a short period of time. We are the first to show that these results contradict the hypertrophy hypothesis, which postulates that cell hypertrophy has negative impact on cell 

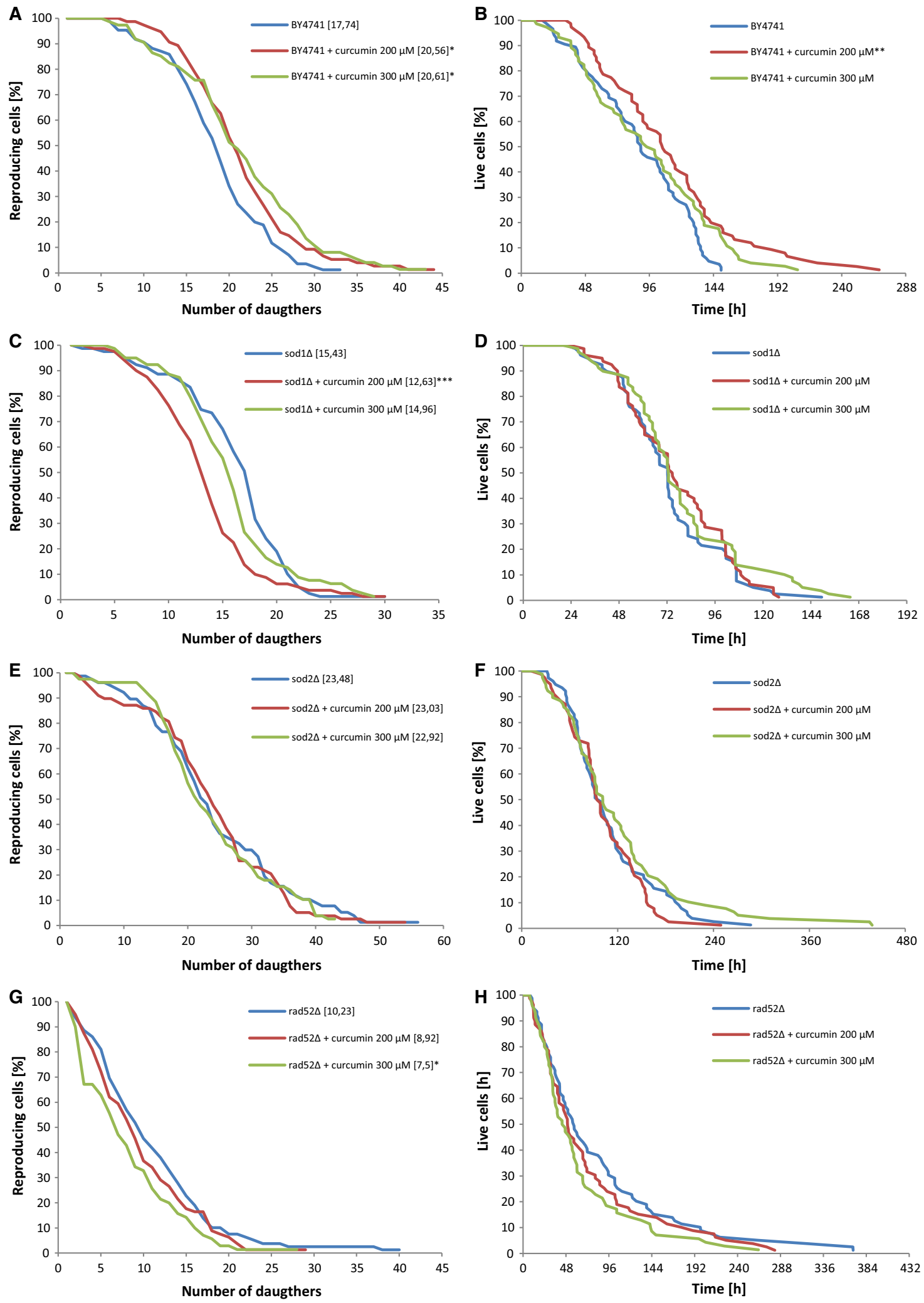
4Fig. 2 Comparison of the budding lifespan (a, c, e, g) and the total lifespan $(\mathbf{b}, \mathbf{d}, \mathbf{f}, \mathbf{h})$ of the haploid wild-type yeast strain BY4741 and isogenic mutant strains $\operatorname{sod} 1 \Delta, \operatorname{sod} 2 \Delta, \operatorname{rad} 52 \Delta$ treated with curcumin. The values in parentheses are the mean values (for total 90 cells from two independent experiments) of the budding lifespan (a, c, e, g). Statistical significance was assessed using ANOVA and the Dunnett's post hoc test $(* \mathrm{p}<0.05, * * \mathrm{p}<0.01, * * * \mathrm{p}<0.001)$ compared to the control (untreated)

function and survival of the organism (Bilinski and Bartosz 2006). Curcumin has also influence on human cells. It was shown that $50 \mu \mathrm{M}$ curcumin induced apoptosis, caused cell cycle arrest in G1-phase and increased the volume of human colorectal adenocarcinoma HT-29 cells (Kossler et al. 2012).

It is worth emphasising that the curcumin concentrations used by us are much higher than those used in other studies, e.g. in mammalian cell lines. As shown by Minear et al. 2011, we can notice the growth inhibiting effect in yeast only from the concentration of approx. $150 \mu \mathrm{M}$.
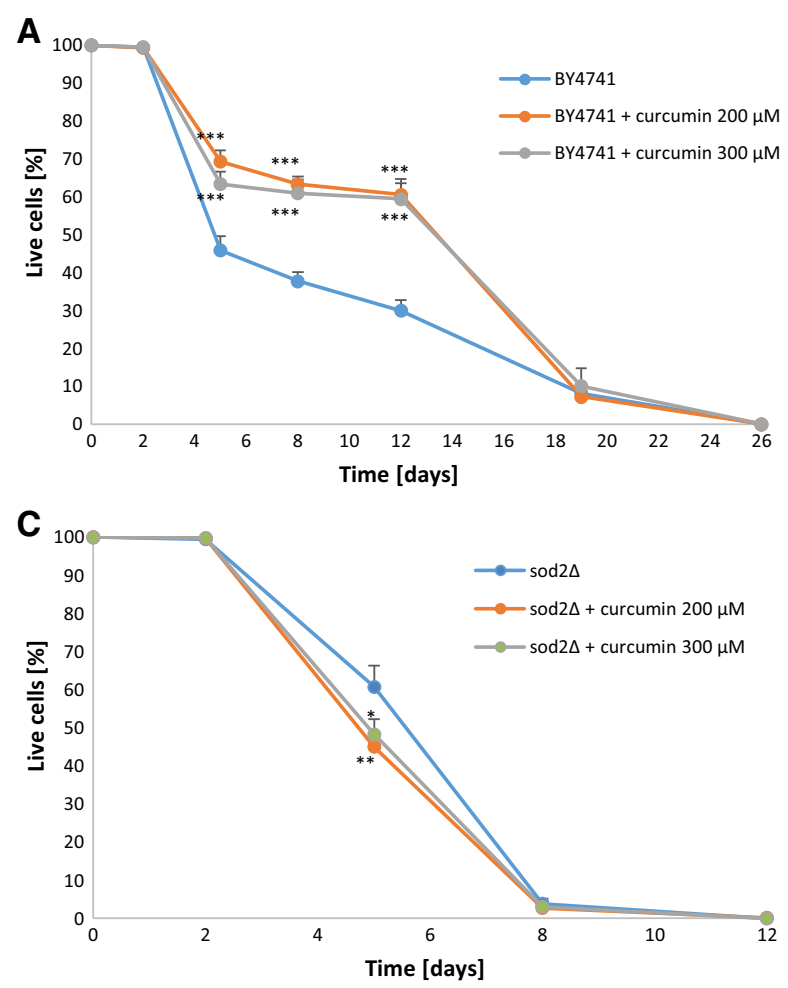

Fig. 3 Chronological lifespan of the haploid wild-type yeast strain BY4741 (a) and isogenic mutant strains $\operatorname{sod} 1 \Delta$ (b), sod $2 \Delta$ (c), $\operatorname{rad} 52 \Delta$ (d) treated with curcumin. Survival was determine by propidium iodide staining. Statistical significance was
Compared to yeast, the fruit fly (Drosophila melanogaster) has been much better and understood as a model organism for analysing impact of curcumin on aging and lifespan. Studies based on that model demonstrated that curcumin extended lifespan of the fruit fly (Lee et al. 2010). As shown by Lee et al., curcumin supplementation contributed to lifespan extension depending on gender and genotype (Lee et al. 2010). It did not affect nutrition habits or fertility of the tested subjects but had a protective effect against oxidative stress, with higher survival rates among individuals exposed to oxidants after prior curcumin treatment. Curcumin supplementation caused a delay in the onset of expression of agerelated genes (Lee et al. 2010). Other studies also demonstrated that the average length of life of the fruit fly was extended in a dose-dependent way and that the effect was connected with the increased activity of superoxide dismutase (SOD), and therefore with protection against free radicals (Suckow and Suckow 2006). Also, Shen et al. noted fruit fly lifespan
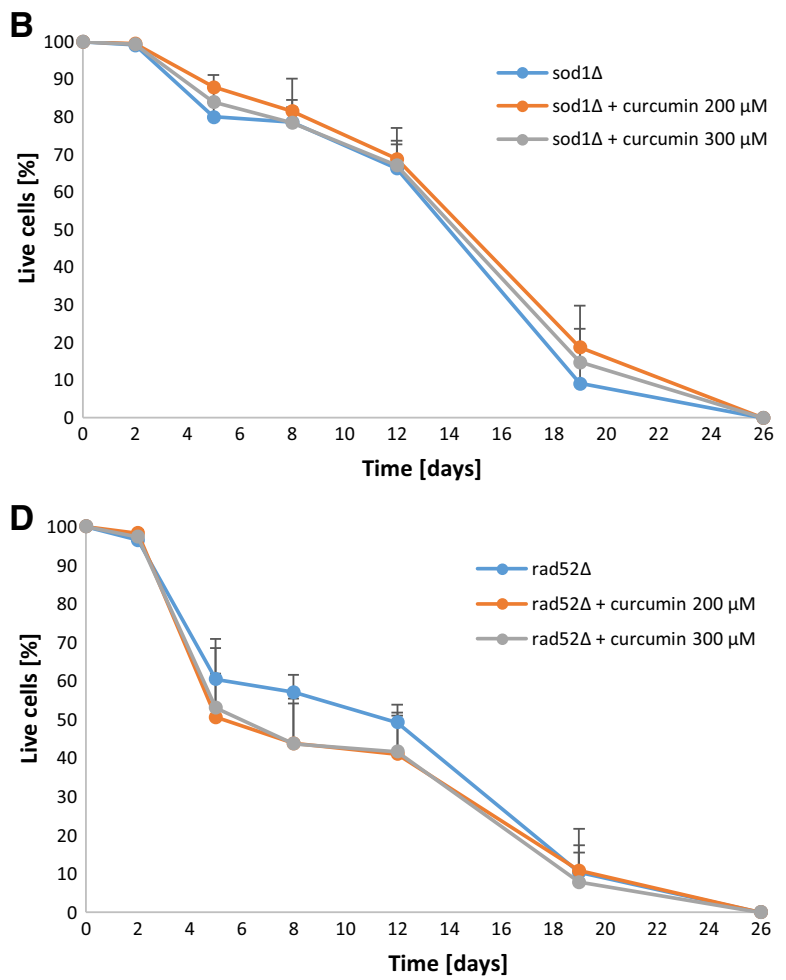

assessed using ANOVA and the Dunnett's post hoc test $(* * \mathrm{p}<0.01, * * * \mathrm{p}<0.001)$ compared to the control (untreated). Bars indicate SD 


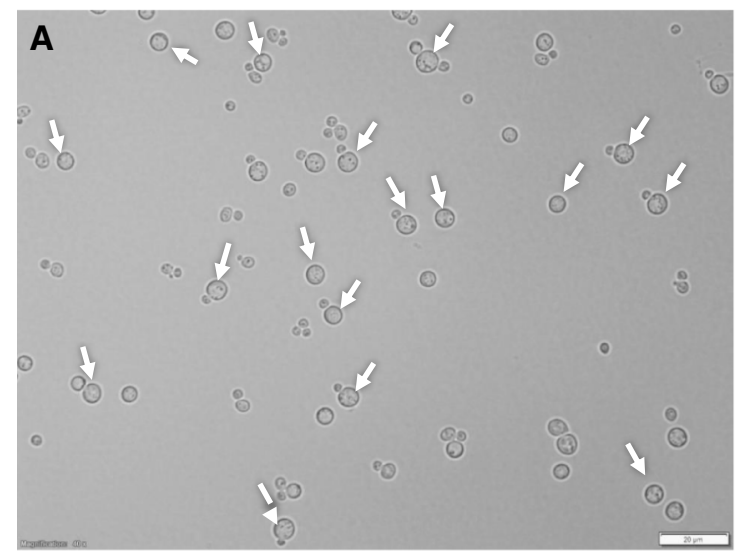

C $\square$ BY4741 $\square$ BY4741 + curcumin $200 \mu \mathrm{M} \quad \mathrm{BY}+$ curcumin $300 \mu \mathrm{M}$

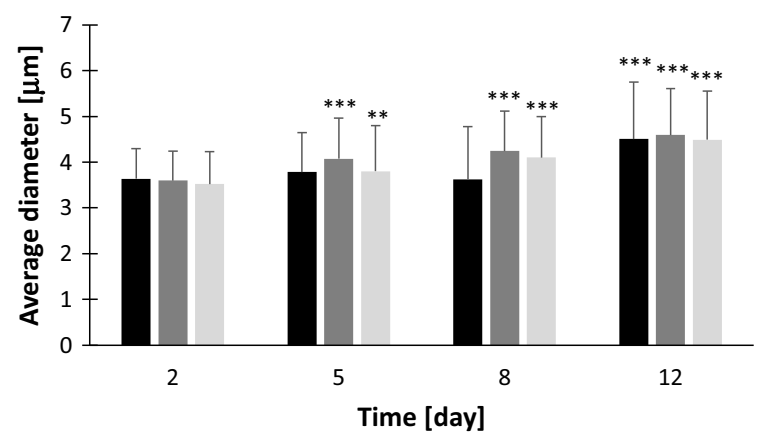

E $\square \operatorname{sod} 2 \Delta \square \operatorname{sod} 2 \Delta+\operatorname{curcumin} 200 \mu \mathrm{M} \backsim \operatorname{sod} 2 \Delta+\operatorname{curcumin} 300 \mu \mathrm{M}$

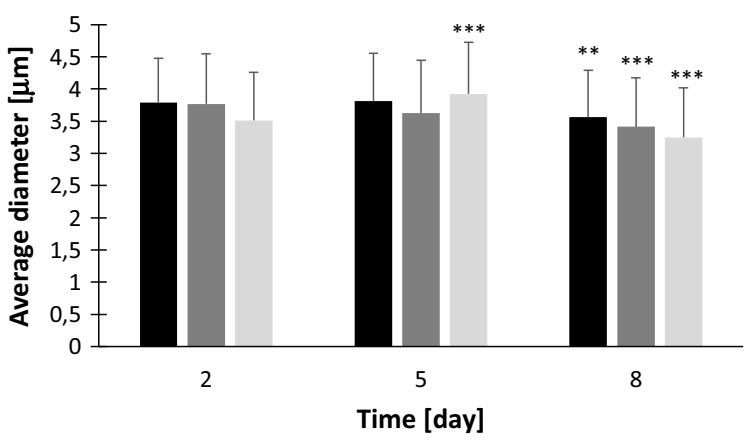

Fig. 4 Changes in cells diameter during chronological lifespan. Only hypertrophic cells are able to survive. Representative image with propidium iodide staining of BY4741 with $200 \mathrm{mM}$ curcumin treated $(\mathbf{a}, \mathbf{b})$. Cells growth up during stopping cell

prolongation and increased SOD activity after curcumin supplementation. In addition, the level of malon dialdehyde (MDA) was evaluated. Average MDA levels in aging individuals (both male and female) were lowered in a way dependent on curcumin concentration and negatively correlated with age (Shen et al. 2013). Due to antioxidant properties of

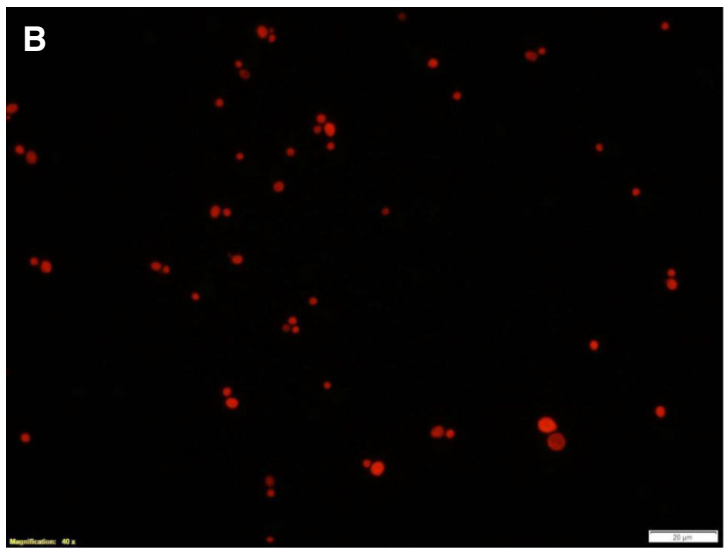

D $\square \operatorname{sod} 1 \Delta \square \operatorname{sod} 1 \Delta+$ curcumin $200 \mu \mathrm{M} \backsim \operatorname{sod} 1 \Delta+$ curcumin $300 \mu \mathrm{M}$

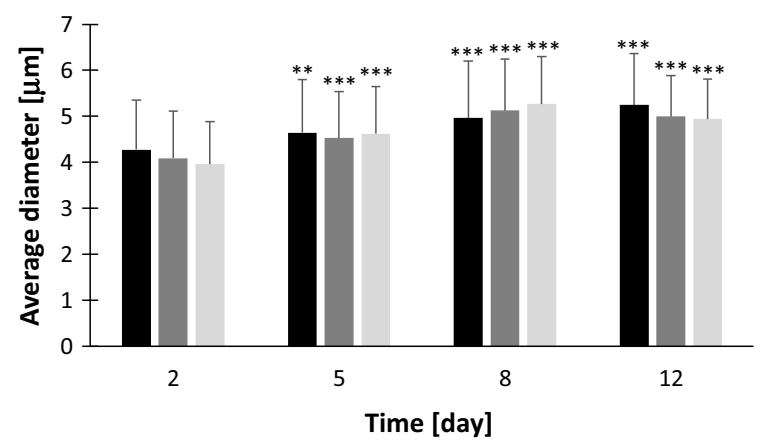

F $\square \operatorname{rad} 52 \Delta \square \operatorname{rad} 52 \Delta+\operatorname{curcumin} 200 \mu \mathrm{M} \backsim \operatorname{rad5} 2 \Delta+$ curcumin $300 \mu \mathrm{M}$

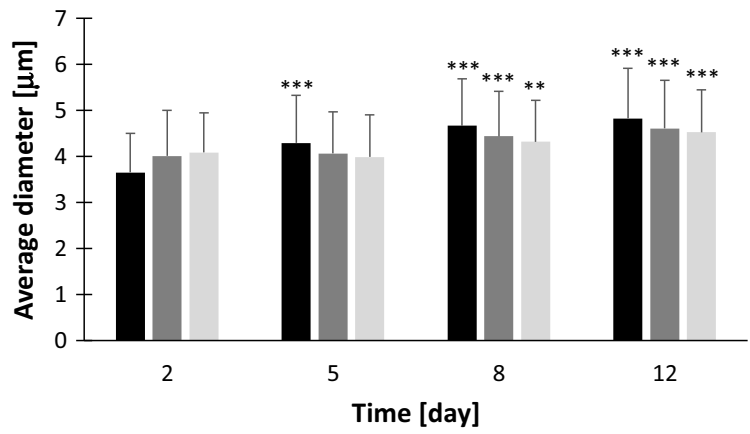

cycle (c-f). Statistical significance was assessed using ANOVA and the Dunnett's post hoc test $(* * \mathrm{p}<0.01, * * * \mathrm{p}<0.001)$ compared to the control (2 day). Bars indicate SD. Arrow indicate hypertrophic live cells

curcumin, its effect on viability of fruit flies exposed to radiation was also evaluated. It turned out that administration of curcumin to the tested individuals protects their cells against damage caused by radiotherapy and extends their lives, and therefore may provide effective protection against radiation (Seong et al. 2015). In addition to analysis of anti-oxidative 
action, the studies also included analysis of acetylcholinesterase (AChE) activity in relation to extension of the fruit fly's life. A curcumin-enriched diet improved the survival capacity of the individuals; moreover, activity of superoxide dismutase and catalase increased while activity of acetylcholinesterase simultaneously decreased (Akinyemi et al. 2018).

The length of life of the Caenorhabditis elegans nematode may also be regulated by curcumin. Curcumin treatment may prolong the life of the adult individual and delay its aging (Liao et al. 2011). Particularly, the average and maximum lifespans are extended. The effect is ascribed to anti-oxidative properties of curcumin, as the intracellular level of ROS and lipofuscin was significantly reduced, which suggests that curcumin may slow down aging in the nematode. In addition, it was found out that curcumin has an impact on the size of the body and the esophageal pumping rate in nematodes. The length of the body in individuals receiving curcumin supplementation became shorter and the esophageal pumping rate became lower, which suggests that curcumin has an impact on nutritional behaviours of the nematode in the manner typical for calorie restriction. No changes in reproduction capacity were noted in comparison to the control. Furthermore, curcumin extended the lives of mutants hypersensitive to oxidative stress (Liao et al. 2011). Curcumin supplementation significantly increases survival of nematodes exposed to oxidative stress (Yu et al. 2014). It also prevents induced oxidative stress by intracellular scavenging of free radicals, including in mutants hypersensitive to oxidation. Exposure to curcumin strengthened expression of heat shock proteins ( $\mathrm{Yu}$ et al. 2014). Extension of life and the related delay in aging in $C$. elegans due to curcumin is attributed mainly to its anti-oxidative properties and capability of reduction of the intracellular free radicals level.

Studies conducted on mammals confirm the argument of pro-health and anti-aging properties of curcumin. Bala et al. evaluated the impact on curcumin on parameters related to aging in brains of rats (Bala et al. 2006). Administration of turmeric to 6-month old and 24-month old rats resulted in a significant decrease in the content of lipid peroxides and lipofuscin in brain regions, while anti-oxidative enzymes such as superoxide dismutase (SOD), glutathione peroxidase and $\mathrm{Na}+/ \mathrm{K}+-$ ATPase demonstrated a substantial increase in brain area activity.
Changes in those age-related parameters show the anti-aging and neuroprotection properties of curcumin (Bala et al. 2006). The focus of the studies was also to determine whether curcumin can neutralise aluminium-induced aging changes in rats. The animals were administered curcumin and aluminium simultaneously; afterwards, their brains were measured to check for age-related parameters. It was found out that curcumin counteracted the neurotoxic action of aluminium (Sharma et al. 2009). Curcumin prevented aluminium-induced increase of lipid peroxidation and inhibition of activity of superoxide dismutase, glutathione peroxidase, glutathione transferase and $\mathrm{Na}+$ / $\mathrm{K}+-$ ATPase in the brain areas of rats. Additionally, it prevented the increase in the activity of acetylcholinesterase and protein kinase $C$ caused by aluminium (Sharma et al. 2009). Thus, curcumin has a protective effect against aluminium-induced strengthening of aging processes and age-related changes in rats by modulation of anti-oxidative parameters (Sharma et al. 2009).

Another target of curcumin which can contribute to alleviation of aging is the AMPK/UCP2 pathway $(\mathrm{Pu}$ et al. 2013). Ucp2 plays a key role in regulation of the production of reactive oxygen species and is connected with delay of aging process. Curcumin increases the AMPK and UCP2 phosphorylation levels in the brains of aging rats. Activation of the AMPK/UCP2 pathway by means of curcumin supplementation lowers the production of superoxide anion, while simultaneously increasing the production of nitric oxide in the endothelial cells of cerebral blood vessels. Because of its anti-oxidative action, curcumin reduces production of ROS and provides protection against dysfunction of cerebrovascular endothelium through the AMPK/UCP2 pathway in rodents and thus alleviates the progress of aging (Pu et al. 2013). The anti-aging role of curcumin in the mammalian model is also manifested by modulation of inflammation markers. Proinflammatory marker levels after curcumin treatment in rats were significantly lower compared to the control (Shailaja et al. 2017). In old rats treated with curcumin, anti-oxidative abilities and superoxide dismutase activity were higher, which shows that anti-oxidative activities of curcumin reduce inflammatory states related to age and that curcumin may have anti-aging effect (Shailaja et al. 2017). Curcumin delays aging and enhances fitness of 


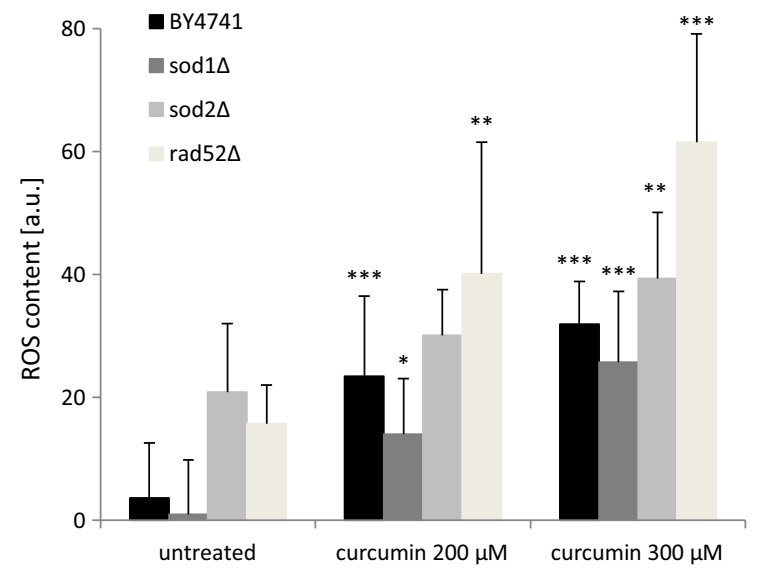

Fig. 5 Superoxide anion content was estimated with the fluorescent probe dihydroethidine for yeast cells grown on liquid medium with curcumin supplementation. Statistical significance was assessed using ANOVA and the Dunnett's post hoc test $(* * \mathrm{p}<0.01, * * * \mathrm{p}<0.001)$ compared to the control (untreated). Bars indicate SD

aging rats mainly due to its anti-oxidative properties and improvement of the cell redox state.

Impact of curcumin on the ROS level in yeast cells

Curcumin has often been described as an anti-oxidative substance. Our aim was to verify whether curcumin is capable of lowering the level of ROS in the Saccharomyces cerevisiae yeast cells. The results proved to be quite surprising. As seen in Fig. 5, curcumin supplementation at both concentrations caused a statistically significant increase in the level of ROS in the cell measured by DHE. Thus, we demonstrate that curcumin has doubtful anti-oxidative effect in the yeast model. We further support this statement by demonstrating the growth on the YPD medium with addition of curcumin after cell incubation with $5 \mathrm{mM} \mathrm{H}_{2} \mathrm{O}_{2}$, which is a strong oxidant. As shown in Table 1, the presence of curcumin also increases cell sensitivity to SDS, which, as demonstrated by Messina et al., also has oxidising properties (Messina et al. 2014). It seems that curcumin also increases cell resistance to Congo red in all of the analysed strains, and especially in the highest concentration, which indicates the influence of yeast cell wall biogenesis. Curcumin also decreases resistance of yeast cells, mainly the $\operatorname{sod} 1 \Delta$ and $\operatorname{sod} 2 \Delta$ mutants, to acetic acid. Interestingly, curcumin has little or no effect on osmotic and thermal stress. In general yeast has a rather low sensitivity because growth inhibition was achieved only with high concentrations, as shown in this study. Previous studies have shown that curcumin generates ROS in several cancer cells and

Table 1 Sensitivity of the BY4741 strain and isogenic mutant strains $\operatorname{sod} 1 \Delta, \operatorname{sod} 2 \Delta, \operatorname{rad} 52 \Delta$ treated with curcumin on cells stressed factors

\begin{tabular}{|c|c|c|c|c|c|c|c|c|c|}
\hline \multirow[t]{2}{*}{ Strain } & \multicolumn{9}{|c|}{ Growth conditions } \\
\hline & YPD & $\begin{array}{l}\text { Congo red } \\
100 \mu \mathrm{g} / \mathrm{mL}\end{array}$ & $\begin{array}{l}\text { MMS } \\
0.03 \%\end{array}$ & $\begin{array}{l}\mathrm{NaCl} \\
1 \mathrm{M}\end{array}$ & $\begin{array}{l}\mathrm{H} 2 \mathrm{O} 2 \\
5 \mathrm{mM}\end{array}$ & $\begin{array}{l}\text { SDS } \\
0.01 \%\end{array}$ & $\begin{array}{l}\text { SDS } \\
0.02 \%\end{array}$ & $\begin{array}{l}\text { Acetic acid } \\
40 \mathrm{mM}\end{array}$ & $\begin{array}{l}\text { Heat } \\
\text { shock }\end{array}$ \\
\hline BY4741 & ++++ & ++ & +++ & +++ & +++ & ++++ & +++ & ++++ & ++++ \\
\hline BY4741 + curcumin $200 \mu \mathrm{M}$ & ++++ & ++ & +++ & +++ & ++ & ++++ & +++ & ++++ & ++++ \\
\hline BY4741 + curcumin $300 \mu \mathrm{M}$ & ++++ & +++ & +++ & +++ & ++ & +++ & ++ & +++ & ++++ \\
\hline $\operatorname{sod} 1 \Delta$ & ++++ & + & +++ & +++ & ++ & +++ & +++ & +++ & ++++ \\
\hline $\operatorname{sod} 1 \Delta+$ curcumin $200 \mu \mathrm{M}$ & ++++ & + & +++ & ++ & + & +++ & ++ & ++ & ++++ \\
\hline $\operatorname{sod} 1 \Delta+$ curcumin $300 \mu \mathrm{M}$ & ++++ & ++ & +++ & ++ & + & ++ & + & + & ++++ \\
\hline $\operatorname{sod} 2 \Delta$ & ++++ & ++ & +++ & +++ & ++ & +++ & +++ & +++ & ++++ \\
\hline $\operatorname{sod} 2 \Delta+$ curcumin $200 \mu \mathrm{M}$ & ++++ & +++ & +++ & +++ & + & +++ & ++ & +++ & ++++ \\
\hline $\operatorname{sod} 2 \Delta+$ curcumin $300 \mu \mathrm{M}$ & ++++ & +++ & +++ & +++ & + & ++ & + & ++ & ++++ \\
\hline $\operatorname{rad} 52 \Delta$ & ++++ & + & - & +++ & + & +++ & +++ & +++ & ++++ \\
\hline $\operatorname{rad} 52 \Delta+$ curcumin $200 \mu \mathrm{M}$ & ++++ & ++ & - & +++ & + & +++ & ++ & +++ & ++++ \\
\hline $\operatorname{rad52} \Delta+$ curcumin $300 \mu \mathrm{M}$ & ++++ & ++ & - & +++ & + & ++ & + & +++ & ++++ \\
\hline
\end{tabular}

Cells were cultured overnight in liquid YPD medium, counted and diluted serially to obtain suspensions at the densities $10^{7}, 10^{6}, 10^{5}$ and $10^{4}$ cell $/ \mathrm{mL}$. Five microliters of each suspension was spotted at YPD solid medium containing various concentrations of curcumin and analyzed toxic factors. Plates were cultivated 2 days in $28{ }^{\circ} \mathrm{C}$. Each " + " means the growth of one spot containing respectively: 50,000, 5000, 500, 50 cells 
triggers apoptosis (Patel et al. 2015, Zhang et al. 2015). Curcumin induced oxidative stress also in bovine leucocytes transformed by Theileria annulata (Araveti and Srivastava 2019). Our results may be explained by the fact that the effect of curcumin is strongly dependent on its concentration. Curcumin is a hormetin, which means that it can be beneficial at a low concentration but have a harmful effect at higher concentrations. Hormetins cause mild stress and eventually trigger hormesis, which is regarded as a promising strategy for slowing down the aging process and prevention or delay of age-related diseases. The presence of curcumin inside or outside the cell may be interpreted as a disorder or stress disrupting the cellular homeodynamics, thus initiating one or more stress response pathways in order to restore the homeodynamic balance (Demirovic and Rattan 2011). Numerous studies have shown that sensitivity to curcumin depends on the type of cell and, most probably, the cell cycle phase. In the in vitro studies, curcumin is toxic for all types of cells within a specific concentration range, while in another range it inhibits the cell cycle; at lower concentrations it seems to have no visible effect on cells (potentially beneficial doses according to curcumin activity).

In conclusion, our studies for the first time indicate that curcumin can influence on yeast replicative and chronological aging. Curcumin accelerates replicative and chronological aging yeast cells devoid of antioxidative protection (with SOD1 and SOD2 gene deletion) and deprived of DNA repair mechanisms (RAD52) but not in the case wild-type cells. Our studies show that yeast cells can achieve longevity when antioxidant systems and DNA repair systems are working properly. We have further shown that hyperthrophic cells allow survive yeast during chronological aging probably via high resistance to enviromental stress factors, e.g. acetic acid. Additionally, curcumin induce oxidative stress in dose dependent manner. It seems that further research is necessary to prove that it is curcumin itself and not the breakdown products of this compound that have a beneficial effect on cells.

\section{Compliance with ethical standards}

Conflict of interest No potential conflict of interest was reported by the authors.

Open Access This article is distributed under the terms of the Creative Commons Attribution 4.0 International License (http:// creativecommons.org/licenses/by/4.0/), which permits unrestricted use, distribution, and reproduction in any medium, provided you give appropriate credit to the original author(s) and the source, provide a link to the Creative Commons license, and indicate if changes were made.

\section{References}

Aggarwal BB, Shishodia S, Takada Y, Banerjee S, Newman RA, Bueso-Ramos CE, Price JE (2005) Curcumin suppresses the paclitaxel-induced nuclear factor-kappa B pathway in breast cancer cells and inhibits lung metastasis of human breast cancer in nude mice. Clin Cancer Res 11:7490-7498

Akinyemi AJ, Oboh G, Ogunsuyi O, Abolaji AO, Udofia A (2018) Curcumin-supplemented diets improve antioxidant enzymes and alter acetylcholinesterase genes expression level in Drosophila melanogaster model. Metab Brain Dis 33:369-375

Araveti PB, Srivastava A (2019) Curcumin induced oxidative stress causes autophagy and apoptosis in bovine leucocytes transformed by Theileria annulata. Cell Death Discov 5:100

Arbiser JL, Klauber N, Rohan R, van Leeuwen R, Huang MT, Fisher C, Flynn E, Byers HR (1998) Curcumin is an in vivo inhibitor of angiogenesis. Mol Med 4:376-383

Azad GK, Singh V, Golla U, Tomar RS (2013) Depletion of cellular iron by curcumin leads to alteration in histone acetylation and degradation of Sml1p in Saccharomyces cerevisiae. PLoS ONE 8:e59003

Azad GK, Singh V, Thakare MJ, Baranwal S, Tomar RS (2014) Mitogen-activated protein kinase Hog1 is activated in response to curcumin exposure in the budding yeast $\mathrm{Sac}$ charomyces cerevisiae. BMC Microbiol 14:317

Bala K, Tripathy BC, Sharma D (2006) Neuroprotective and anti-ageing effects of curcumin in aged rat brain regions. Biogerontology 7:81-89

Barchitta M, Maugeri A, Favara G, San Lio RM, Evola G, Agodi A, Basile G (2019) Nutrition and wound healing: an overview focusing on the beneficial effects of curcumin. Int J Mol Sci 20:1119

Beevers CS, Li FJ, Liu L, Huang SL (2006) Curcumin inhibits the mammalian target of rapamycin-mediated signaling pathways in cancer cells. Int J Cancer 119:757-764

Bilinski T, Bartosz G (2006) Hypothesis: cell volume limits cell divisions. Acta Biochim Pol 53:833-835

Boyanapalli SS, Kong AT (2015) Curcumin, the King of spices: epigenetic regulatory mechanisms in the prevention of cancer, neurological, and inflammatory diseases. Curr Pharmacol Rep. 1(2):129-139

Cole GM, Schild D, Mortimer RK (1989) 2 DNA-repair and recombination genes in Saccharomyces-cerevisiae, $\operatorname{rad} 52$ and rad54, are induced during meiosis. Mol Cell Biol 9:3101-3104

Demirovic D, Rattan SIS (2011) Curcumin induces stress response and hormetically modulates wound healing ability of human skin fibroblasts undergoing ageing in vitro. Biogerontology 12:437-444 
Duvoix A, Blasius R, Delhalle S, Schnekenburger M, Morceau F, Henry E, Dicato M, Diederich M (2005) Chemopreventive and therapeutic effects of curcumin. Cancer Lett 223:181-190

Fabrizio P, Longo VD (2003) The chronological life span of Saccharomyces cerevisiae. Aging Cell 2:73-81

Fukai T, Ushio-Fukai M (2011) Superoxide dismutases: role in redox signaling, vascular function, and diseases. Antioxid Redox Signal 15:1583-1606

Gupta SC, Patchva S, Koh W, Aggarwal BB (2012) Discovery of curcumin, a component of golden spice, and its miraculous biological activities. Clin Exp Pharmacol Physiol 39:283-299

Harman D (1956) Aging - a theory based on free-radical and radiation-chemistry. J Gerontol 11:298-300

Hewlings SJ, Kalman DS (2017) Curcumin: a review of its' effects on human health. Foods 6:92

$\mathrm{Hu}$ A et al (2017) Curcumin induces G2/M cell cycle arrest and apoptosis of head and neck squamous cell carcinoma in vitro and in vivo through ATM/Chk2/p53-dependent pathway. Oncotarget 8:50747-50760

Jaiswal AS, Marlow BP, Gupta N, Narayan S (2002) betaCatenin-mediated transactivation and cell-cell adhesion pathways are important in curcumin (diferuylmethane)induced growth arrest and apoptosis in colon cancer cells. Oncogene 21:8414-8427

Kaeberlein M (2010) Lessons on longevity from budding yeast. Nature 464:513-519

Kossler S, Nofziger C, Jakab M, Dossena S, Paulmichl M (2012) Curcumin affects cell survival and cell volume regulation in human renal and intestinal cells. Toxicology 292:123-135

Lantto TA, Colucci M, Zavadova V, Hiltunen R, Raasmaja A (2009) Cytotoxicity of curcumin, resveratrol and plant extracts from basil, juniper, laurel and parsley in SH-SY5Y and CV1-P cells. Food Chem 117:405-411

Lee KS, Lee BS, Semnani S, Avanesian A, Um CY, Jeon HJ, Seong KM, Yu K, Min KJ, Jafari M (2010) Curcumin extends life span, improves health span, and modulates the expression of age-associated aging genes in Drosophila melanogaster. Rejuvenation Res 13:561-570

Liao VHC, Yu CW, Chu YJ, Li WH, Hsieh YC, Wang TT (2011) Curcumin-mediated lifespan extension in Caenorhabditis elegans. Mech Ageing Dev 132:480-487

Menon VP, Sudheer AR (2007) Antioxidant and anti-inflammatory properties of curcumin. Mol Targets Ther Curcumin Health Dis 595:105-125

Messina CM, Faggio C, Laudicella VA, Sanfilippo M, Trischitta F, Santulli A (2014) Effect of sodium dodecyl sulfate (SDS) on stress response in the Mediterranean mussel (Mytilus Galloprovincialis): regulatory volume decrease (Rvd) and modulation of biochemical markers related to oxidative stress. Aquat Toxicol 157:94-100

Minear S, O'Donnell AF, Ballew A, Giaever G, Nislow C, Stearns T, Cyert MS (2011) Curcumin inhibits growth of Saccharomyces cerevisiae through iron chelation. Eukaryot Cell 10:1574-1581

Minois N, Frajnt M, Wilson C, Vaupel JW (2005) Advances in measuring lifespan in the yeast Saccharomyces cerevisiae. Proc Natl Acad Sci USA 102:402-406. https://doi.org/10. 1073/pnas.0408332102
Molon M, Szajwaj M, Tchorzewski M, Skoczowski A, Niewiadomska E, Zadrag-Tecza R (2016) The rate of metabolism as a factor determining longevity of the Saccharomyces cerevisiae yeast. Age 38:11

Molon M, Panek A, Molestak E, Skoneczny M, Tchorzewski M, Wnuk M (2018) Daughters of the budding yeast from old mothers have shorter replicative lifespans but not total lifespans. Are DNA damage and rDNA instability the factors that determine longevity? Cell Cycle 17:1173-1187

Patel PB, Thakkar VR, Patel JS (2015) Cellular effect of curcumin and citral combination on breast cancer cells: induction of apoptosis and cell cycle arrest. J Breast Cancer 18:225-234

Plummer SM, Holloway KA, Manson MM, Munks RJL, Kaptein A, Farrow S, Howells L (1999) Inhibition of cyclooxygenase 2 expression in colon cells by the chemopreventive agent curcumin involves inhibition of NF-kappa B activation via the NIK/IKK signalling complex. Oncogene 18:6013-6020

$\mathrm{Pu}$ YF et al (2013) Dietary curcumin ameliorates aging-related cerebrovascular dysfunction through the AMPK/uncoupling protein 2 pathway. Cell Physiol Biochem 32:1167-1177

Seong KM, Yu M, Lee KS, Park S, Jin Y, Min KJ (2015) Curcumin mitigates accelerated aging after irradiation in Drosophila by reducing oxidative stress. Biomed Res Int 2015:425380

Shailaja M, Gowda KMD, Vishakh K, Kumari NS (2017) Antiaging role of curcumin by modulating the inflammatory markers in albino wistar rats. J Natl Med Assoc 109:9-13

Sharma D, Sethi P, Hussain E, Singh R (2009) Curcumin counteracts the aluminium-induced ageing-related alterations in oxidative stress, $\mathrm{Na}(+), \mathrm{K}(+)$ ATPase and protein kinase $\mathrm{C}$ in adult and old rat brain regions. Biogerontology 10:489-502

Shen LR, Xiao F, Yuan P, Chen Y, Gao QK, Parnell LD, Meydani M, Ordovas JM, Li D, Lai CQ (2013) Curcuminsupplemented diets increase superoxide dismutase activity and mean lifespan in Drosophila. Age 35:1133-1142

Shishodia S, Aggarwal BB (2002) Nuclear factor-kappa B activation: a question of life or death. J Biochem Mol Biol $35: 28-40$

Suckow BK, Suckow MA (2006) Lifespan extension by the antioxidant curcumin in Drosophila melanogaster. Int $\mathrm{J}$ Biomed Sci 2(4):402-405

Toda S, Miyase T, Arichi H, Tanizawa H, Takino Y (1985) Natural antioxidants. 13. Antioxidative components isolated from rhizome of curcuma-longa 1. Chem Pharm Bull 33:1725-1728

Wei QY, Chen WF, Zhou B, Yang L, Liu ZL (2006) Inhibition of lipid peroxidation and protein oxidation in rat liver mitochondria by curcumin and its analogues. Biochimica Et Biophysica Acta-Gener Subj 1760:70-77

Yu CW, Wei CC, Liao VHC (2014) Curcumin-mediated oxidative stress resistance in is modulated by age- 1 , akt-1, pdk-1, osr-1, unc-43, sek-1, skn-1, sir-2.1, and mev-1. Free Radic Res 48:371-379

Zadrag R, Bartosz G, Bilinski T (2008) Is the yeast a relevant model for aging of multicellular organisms? An insight from the total lifespan of Saccharomyces cerevisiae. Curr Aging Sci 1(3):159-165 
Zhang XH et al (2015) Curcumin analog WZ35 induced cell death via ROS-dependent ER stress and G2/M cell cycle arrest in human prostate cancer cells. BMC Cancer 15:866

Zhu YP, Bu SR (2017) Curcumin induces autophagy, apoptosis, and cell cycle arrest in human pancreatic cancer cells. Evid-Based Complement Altern Med 2017:5787218
Publisher's Note Springer Nature remains neutral with regard to jurisdictional claims in published maps and institutional affiliations. 